\title{
Treatment Outcomes in the Tube Versus Trabeculectomy (TVT) Study After Five Years of Follow-up
}

\author{
Steven J. Gedde, M.D. ${ }^{1}$, Joyce C. Schiffman, M.S. ${ }^{1}$, William J. Feuer, M.S. ${ }^{1}$, Leon W. \\ Herndon, M.D. ${ }^{2}$, James D. Brandt, M.D. ${ }^{3}$, Donald L. Budenz, M.D., M.P.H. ${ }^{1}$, and Tube Versus \\ Trabeculectomy Study Group \\ ${ }^{1}$ Bascom Palmer Eye Institute, Miller School of Medicine, University of Miami, Miami, Florida \\ ${ }^{2}$ Department of Ophthalmology, Duke University, Durham, North Carolina \\ ${ }^{3}$ Department of Ophthalmology, University of California, Davis, Sacramento, California
}

\begin{abstract}
Despite the introduction of several new glaucoma operations in recent years, ${ }^{1-4}$ trabeculectomy (or guarded filtration procedure) and tube shunt (or aqueous shunt) surgery remain the most commonly performed incisional procedures for the management of glaucoma. Trabeculectomy has historically been preferred over tube shunt implantation, except in refractory glaucomas at high risk for filtration failure. However, concern about bleb-related complications has contributed to an expanded use of tube shunts as an alternative to trabeculectomy. Medicare claims data show a $43 \%$ decrease in the number of trabeculectomy procedures and a concurrent $184 \%$ increase in tube shunt surgery between 1995 and 2004. ${ }^{5}$ Recent surveys of the American Glaucoma Society membership have demonstrated a rise in the proportion of surgeons using tube shunts and a decline in the popularity of trabeculectomy. ${ }^{6-8}$ These surveys have also indicated a lack of consensus regarding the best surgical approach for managing glaucoma in patients who have undergone prior ocular surgery. In particular, some surgeons favor placement of a tube shunt while others prefer a trabeculectomy with an adjunctive antifibrotic agent in eyes with previous cataract or glaucoma surgery.
\end{abstract}

The Tube Versus Trabeculectomy (TVT) Study was designed to prospectively compare the safety and efficacy of tube shunt surgery and trabeculectomy with mitomycin C (MMC) in eyes with prior ocular surgery. Patients with uncontrolled glaucoma who had previously undergone cataract extraction with intraocular lens implantation and/or failed filtering surgery were enrolled in this multicenter clinical trial and randomized to receive either a 350-mm² Baerveldt glaucoma implant (Abbott Medical Optics, Santa Ana, CA) or a trabeculectomy with MMC. The goal of this investigator-initiated study is to provide

(C) 2011 Elsevier Inc. All rights reserved.

Corresponding author: Steven J. Gedde, M.D., Bascom Palmer Eye Institute, 900 N.W. 17th Street, Miami, Florida 33136. Telephone: 305-326-6435. Fax: 305-326-6478. sgedde@med.miami.edu.

Supplemental material available at AJO.com

Publisher's Disclaimer: This is a PDF file of an unedited manuscript that has been accepted for publication. As a service to our customers we are providing this early version of the manuscript. The manuscript will undergo copyediting, typesetting, and review of the resulting proof before it is published in its final citable form. Please note that during the production process errors may be discovered which could affect the content, and all legal disclaimers that apply to the journal pertain. 
information that will assist in surgical decision making in similar patient groups. This article reports the outcomes of treatment during 5 years of follow-up in the TVT Study.

\section{METHODS}

The design and methods of the TVT Study were previously described in detail, ${ }^{9}$ and they are summarized as follows:

\section{Eligibility Criteria}

Inclusion criteria included age 18 to 85 years, previous trabeculectomy and/or cataract extraction with intraocular lens implantation, and intraocular pressure (IOP) $\geq 18 \mathrm{~mm} \mathrm{Hg}$ and $\leq 40 \mathrm{~mm} \mathrm{Hg}$ on maximum tolerated medical therapy. Exclusion criteria included no light perception vision, pregnant or nursing women, active iris neovascularization or proliferative retinopathy, iridocorneal endothelial syndrome, epithelial or fibrous downgrowth, aphakia, vitreous in the anterior chamber for which a vitrectomy was anticipated, chronic or recurrent uveitis, severe posterior blepharitis, unwillingness to discontinue contact lens use after surgery, previous cyclodestructive procedure, prior scleral buckling procedure, presence of silicone oil, conjunctival scarring precluding a superior trabeculectomy, and need for glaucoma surgery combined with other ocular procedures or anticipated need for additional ocular surgery. Only 1 eye of eligible patients was included in the study.

\section{Randomization and Treatment}

The TVT Study was conducted at 17 Clinical Centers. Eligibility was independently confirmed at the Statistical Coordinating Center. Patients enrolled in the study were randomized to placement of a $350-\mathrm{mm}^{2}$ Baerveldt glaucoma implant or trabeculectomy with MMC. Randomization was performed using a permuted block design stratified by Clinical Center and type of previous intraocular surgery. Neither the patient nor the clinician was masked to the randomization assignment during follow-up.

A $350-\mathrm{mm}^{2}$ Baerveldt glaucoma implant was placed in the superotemporal quadrant in all patients randomized to the tube group. A limbus-based or fornix-based conjunctival flap was dissected, and the implant was sutured to sclera $10 \mathrm{~mm}$ posterior to the limbus. The Baerveldt tube was completely occluded to temporarily restrict flow through the device until encapsulation of the plate occurred. The surgeon was given the option of fenestrating the tube for early IOP reduction. The Baerveldt tube was inserted into the anterior chamber through a 23-gauge needle track. A patch graft was used to cover the limbal portion of the tube, and the conjunctiva was closed.

All patients randomized to the trabeculectomy group underwent a trabeculectomy with mitomycin C superiorly. A limbus-based or fornix-based flap was created, and a fluid retaining sponge soaked in MMC $(0.4 \mathrm{mg} / \mathrm{ml})$ was applied to the superior sclera for 4 minutes. A partial-thickness scleral flap was dissected, and a paracentesis was made. A block of limbal tissue was excised underneath the trabeculectomy flap. The scleral flap was reapproximated to the scleral bed with interrupted or releasable 10-0 nylon sutures. The conjunctiva was closed, and Seidel testing was performed at the conclusion of the case. 


\section{Patient Visits}

Baseline demographic and clinical information were collected for enrolled patients. Followup visits were scheduled at 1 day, 1 week, 1 month, 3 months, 6 months, 1 year, 18 months, 2 years, 3 years, 4 years, and 5 years postoperatively. Each examination included measurement of Snellen visual acuity (VA), IOP, slit lamp biomicroscopy, Seidel testing, and ophthalmoscopy. Humphrey perimetry, Early Treatment Diabetic Retinopathy Study (ETDRS) VA, and quality of life using the National Eye Institute-Visual Function Questionnaire (NEI VFQ-25) were assessed at baseline and at the annual follow-up visits. A formal motility evaluation was performed in all patients at baseline and at the 1-year and 5year follow-up visits, and at any visit after 3 months at which the patient reported diplopia. Investigators provided an explanation for loss of 2 or more lines of Snellen VA at follow-up visits after 3 months. Postoperative interventions and surgical complications were documented at each follow-up visit. Additional information was collected for patients undergoing a reoperation, including the date of surgery, type of procedure, and IOP level and number of glaucoma medications immediately prior to reoperation.

\section{Outcome Measures}

Outcome measures assessed in the TVT Study include IOP, VA, use of supplemental medical therapy, surgical complications, visual fields, quality of life, and failure. Failure was prospectively defined as IOP $>21 \mathrm{~mm} \mathrm{Hg}$ or less than $20 \%$ reduction below baseline on 2 consecutive follow-up visits after 3 months, IOP $\leq 5 \mathrm{~mm} \mathrm{Hg}$ on 2 consecutive follow-up visits after 3 months, reoperation for glaucoma, or loss of light perception vision.

Reoperation for glaucoma was defined as additional glaucoma surgery requiring a return to the operating room, such as placement of a tube shunt. Cyclodestruction was also counted as a reoperation for glaucoma. Interventions performed at the slit lamp, such as needling procedures and laser suture lysis, were not considered glaucoma reoperations. Eyes that had not failed by the above criteria and were not on supplemental medical therapy were considered complete successes. Eyes that had not failed but required supplemental medical therapy were defined as qualified successes. An independent Safety and Data Monitoring Committee (SDMC) met twice a year to monitor the conduct of the study.

\section{Statistical Analysis}

Univariate comparisons between treatment groups were performed using the two-sided Student t-test for continuous variables and the chi-square test, Fisher's exact test, or exact permutation chi-square test for categorical variables. Snellen VA measurements were converted to $\log$ MAR equivalents for the purpose of data analysis, as reported previously. ${ }^{10}$ The time to failure was defined as the time from surgical treatment to reoperation for glaucoma, loss of light perception vision, or the first of 2 consecutive study visits after 3 months in which the patient had persistent hypotony (IOP $\leq 5 \mathrm{~mm} \mathrm{Hg}$ ) or inadequately reduced IOP (IOP > $21 \mathrm{~mm} \mathrm{Hg}$ or not reduced by $20 \%$ below baseline). Treatment comparisons of time to failure and time to reoperation for glaucoma were assessed with the stratified Kaplan-Meier survival analysis log rank test. Risk factors for failure were evaluated with the Kaplan-Meier survival log rank test. Multivariate analysis was performed 
using Cox proportional hazard regression analysis with forward stepwise elimination. A pvalue of .05 or less was considered statistically significant in our analyses.

\section{RESULTS}

\section{Recruitment and Retention}

The TVT Study enrolled 212 eyes of 212 patients between October 1999 and April 2004. Randomization assigned 107 patients to placement of a 350- $\mathrm{mm}^{2}$ Baerveldt glaucoma implant and 105 patients to a trabeculectomy with MMC. All patients received their assigned treatment.

Figure 1 shows the progress of patients in the study. In the overall study group, 28 (13\%) patients died within 5 years of enrollment. An additional 39 (18\%) patients missed their 5year study visit. During the first 5 years, $13.0 \%$ of follow-up visits were missed because of deaths and losses to follow-up. The visit completion rate did not significantly differ by treatment group ( $\mathrm{p}=.22$, chi-square test).

\section{Baseline Characteristics}

Table 1 presents the baseline characteristics of study patients. No significant differences in any of the demographic or clinical features were observed between treatment groups at enrollment. Additional information on randomized patients was provided in a previous publication. ${ }^{9}$ Similar mean IOPs and glaucoma medications were seen among patients who were and were not lost to follow-up in both treatment groups (supplemental material at AJO.com).

\section{IOP Reduction}

Table 2 and Figure 2 provide baseline and follow-up IOP measurements for the tube and trabeculectomy groups. Patients who underwent additional glaucoma surgery were censored from analysis after reoperation. Both surgical procedures produced a significant and sustained reduction in IOP. At 5 years, IOP (mean $\pm \mathrm{SD}$ ) was $14.4 \pm 6.9 \mathrm{~mm} \mathrm{Hg}$ in the tube group and $12.6 \pm 5.9 \mathrm{~mm} \mathrm{Hg}$ in the trabeculectomy group $(\mathrm{p}=.12$, Student $\mathrm{t}$-test; $95 \%$ confidence interval $-0.5 \mathrm{~mm} \mathrm{Hg}$ to $4.1 \mathrm{~mm} \mathrm{Hg}$ ). Among patients who completed 5-year follow-up visits, IOP reduction from baseline (mean $\pm \mathrm{SD}$ ) was $10.2 \pm 7.4 \mathrm{~mm} \mathrm{Hg}(41.4 \%)$ in the tube group ( $\mathrm{p}<.001$, paired t-test) and $12.4 \pm 7.2 \mathrm{~mm} \mathrm{Hg}(49.5 \%)$ in the trabeculectomy group $(\mathrm{p}<.001$, paired $\mathrm{t}$-test). The degree of IOP reduction was similar between the two treatment groups at 5 years ( $\mathrm{p}=.097$, Student $\mathrm{t}$-test). No significant difference in mean IOP was seen between treatment groups after 3 months. The proportion of patients with IOP $\leq 14 \mathrm{~mm} \mathrm{Hg}$ was also similar between the tube and trabeculectomy groups. At 5 years, 39 (63.9\%) patients in the tube group and $40(63.5 \%)$ patients in the trabeculectomy group had an IOP of $14 \mathrm{~mm} \mathrm{Hg}$ or less ( $\mathrm{p}=1.00$, chi-square test).

An additional intent-to-treat analysis was performed, which included patients who required further surgery for glaucoma. No significant difference in mean IOP was present between treatment groups taking into account all medical and surgical management during 5 years of follow-up. At 5 years, IOP (mean $\pm \mathrm{SD}$ ) was $14.3 \pm 6.8 \mathrm{~mm} \mathrm{Hg}$ in the tube group and $13.6 \pm$ 
$6.2 \mathrm{~mm} \mathrm{Hg}$ in the trabeculectomy group $(\mathrm{p}=.54$, Student t-test; 95\% confidence interval $-1.4 \mathrm{~mm} \mathrm{Hg}$ to $2.8 \mathrm{~mm} \mathrm{Hg}$ ).

\section{Medical Therapy}

Table 2 shows the number of glaucoma medications in the tube and trabeculectomy groups at baseline and follow-up. Patients who underwent additional glaucoma surgery were censored from analysis after reoperation. A significant reduction in the use of medical therapy was seen in both treatment groups. The number of glaucoma medications (mean \pm $\mathrm{SD})$ decreased from baseline by $1.8 \pm 1.8$ in the tube group $(\mathrm{p}<.001$, paired $\mathrm{t}$-test $)$ and $1.7 \pm$ 2.0 in trabeculectomy group $(\mathrm{p}<.001$, paired $\mathrm{t}$-test) in patients who completed 5-year follow-up visits. A significantly greater use of supplemental medical therapy was observed in the tube group compared with the trabeculectomy group at all follow-up visits during the first 2 postoperative years. However, the mean number of glaucoma medications was similar between treatment groups at 3 years and at all subsequent study visits.

No significant difference in the mean number of medications was seen between treatment groups after 5 years of follow-up when patients who underwent additional glaucoma surgery were included in the analysis. The mean number of medications was $1.4 \pm 1.3$ in the tube group and $1.2 \pm 1.4$ in the trabeculectomy group at 5 years in an intent-to-treat analysis ( $p$ $=.25$, Student $\mathrm{t}$-test).

\section{Treatment Outcomes}

Table 3 presents the outcomes of randomized patients, unadjusted for follow-up time. All patients who completed 5-year follow-up visits and/or had a prior failure were included in this analysis. A significantly higher failure rate was seen in the trabeculectomy group than the tube group after 5 years. Treatment failure had occurred in $24(33 \%)$ patients in the tube group and $42(50 \%)$ patients in the trabeculectomy group at 5 years $(\mathrm{p}=.034$, chi-square test adjusted for stratum). In the tube group, 18 (25\%) patients were classified as complete successes and $31(42 \%)$ patients were qualified successes. In the trabeculectomy group, 24 (29\%) patients were complete successes and 18 (21\%) patients were qualified successes. While the tube group had a higher overall success rate after 5 years, the rate of complete success was similar between treatment groups ( $\mathrm{p}=.58$, chi-square test adjusted for stratum).

Kaplan-Meier survival analysis was also used to compare failure rates between the two treatment groups, and the results are presented in Figure 3. The cumulative probability of failure was $29.8 \%$ in the tube group and $46.9 \%$ in the trabeculectomy group at 5 years $(\mathrm{p}=$. $002, \log$ rank test adjusted for stratum; hazards ratio $=2.15 ; 95 \%$ confidence interval $=1.30$ to 3.56). No significant differences in treatment efficacy were found between strata ( $\mathrm{p}=$. 143 , test of treatment-stratum interaction).

Figure 4 presents the failure rates for the two treatment groups using alternative outcome criteria. Patients with persistent hypotony, reoperation for glaucoma, or loss of light perception vision were still classified as treatment failures. However, the upper IOP limit distinguishing success from failure was changed. When inadequate IOP reduction was defined as IOP greater than $17 \mathrm{~mm} \mathrm{Hg}$ or not reduced by $20 \%$ from baseline on 2 consecutive follow-up visits after 3 months, the cumulative probability of failure at 5 years 
was $31.8 \%$ in the tube group and $53.6 \%$ in the trabeculectomy group $(\mathrm{p}=.002, \log$ rank test adjusted for stratum; hazards ratio $=2.04 ; 95 \%$ confidence interval $=1.29$ to 3.24 ). When inadequate IOP reduction was defined as IOP greater than $14 \mathrm{~mm} \mathrm{Hg}$ on 2 consecutive visits after 3 months, the cumulative probability of failure was 52.3\% in the tube group and 71.5\% in the trabeculectomy group at 5 years $(\mathrm{p}=.017, \log$ rank test adjusted for stratum; hazards ratio $=1.57 ; 95 \%$ confidence interval $=1.09$ to 2.26 ). Significantly higher failure rates were observed in the trabeculectomy group compared with the tube group when more stringent IOP criteria were used to define success and failure.

Table 4 lists the reasons for classification as a treatment failure. The most common cause for failure during 5 years of follow-up in both treatment groups was inadequate IOP reduction (IOP > $21 \mathrm{~mm} \mathrm{Hg}$ or not reduced by $20 \%$ below baseline on 2 consecutive follow-up visits after 3 months). There were 6 patients in the trabeculectomy group and 1 patient in the tube group who failed because of inadequate IOP reduction and subsequently underwent reoperation for glaucoma. One patient in the trabeculectomy group who failed because of persistent hypotony subsequently underwent a bleb revision for a bleb leak, and a reoperation for glaucoma was later performed when the bleb failed. Seven patients in the tube group and 11 patients in the trabeculectomy group had a reoperation for glaucoma before meeting the failure criteria for inadequate IOP reduction. Among the patients who failed because of inadequate IOP reduction or glaucoma reoperation, the number of medications (mean $\pm \mathrm{SD}$ ) at the time of failure was $2.2 \pm 1.4$ in the tube group and $2.4 \pm 1.1$ in the trabeculectomy group ( $\mathrm{p}=.54$, Student t-test). Persistent hypotony was the cause for treatment failure in 3 patients in the tube group and 13 patients in the trabeculectomy group. Loss of VA from baseline was seen in 13 (81\%) patients in the overall group of hypotony failures. Despite failing because of hypotony, 2 patients in the trabeculectomy group and 1 patient in the tube group retained their preoperative level of vision throughout the 5 years of follow-up. When the 3 patients with hypotony and stable vision were reclassified as successes instead of failures, the cumulative probability of failure using survival analysis was $28.6 \%$ in the tube group and $44.4 \%$ in the trabeculectomy group at 5 years $(\mathrm{p}=.003$, log rank test adjusted for stratum). Loss of light perception vision occurred in 1 patient in each treatment group. No significant difference in the distribution of reasons for failure was present between treatment groups $(\mathrm{p}=.43$, exact permutation chi-square test).

Baseline demographic and clinical features were evaluated as possible predictors for treatment failure and are shown in Table 5. Treatment failures were pooled from both treatment groups for this risk factor analysis. Only assigned treatment was significantly associated with treatment outcome in univariate analysis $(\mathrm{p}=.002, \log$ rank test). Stratum, age, gender, race, diabetes mellitus, hypertension, lens status, number of previous intraocular surgeries, time since last intraocular surgery, glaucoma type, preoperative number of medications, preoperative IOP, preoperative Snellen VA, and Clinical Centers were not associated with treatment failure either univariately or in a multivariate model adjusted for treatment. Separate risk factor analyses were also performed for each treatment group, and none of the baseline factors predicted failure for tube shunt surgery or trabeculectomy with MMC. 


\section{Reoperation for Glaucoma}

Table 6 presents the reoperations that were performed for glaucoma. A higher rate of reoperation for glaucoma was observed in the trabeculectomy group compared with the tube group. The 5-year cumulative reoperation rate for glaucoma using Kaplan-Meier survival analysis was $9 \%$ in the tube group and $29 \%$ in the trabeculectomy group $(\mathrm{p}=.025$, log-rank test adjusted for stratum). A total of 18 patients in the trabeculectomy group underwent additional glaucoma surgery, which involved placement of a tube shunt in 15 patients, a bleb revision with tube shunt placement in 2 patients, and a trabeculectomy with 5-fluorouracil in 1 patient. One of the patients who received a tube shunt subsequently underwent a transscleral cyclophotocoagulation in the study eye as a second reoperation for glaucoma. In the tube group, 8 patients had glaucoma reoperations, including placement of a second tube shunt in 4 patients, transscleral cyclophotocoagulation in 3 patients, and endocyclophotocoagulation performed in conjunction with cataract surgery in 1 patient. Repeat transscleral cyclophotocoagulation was performed in the patient who had endocyclophotocoagulation.

Because the surgeon was not masked to the treatment assignment, a potential bias existed in the decision to reoperate for glaucoma. To evaluate for selection bias, the IOP levels were compared between treatment groups in patients who underwent glaucoma reoperation, as well as those who failed because of inadequate IOP reduction but did not have additional glaucoma surgery. The IOP (mean $\pm \mathrm{SD}$ ) was $21.1 \pm 5.7 \mathrm{~mm} \mathrm{Hg}$ for the 8 patients in the tube group and $27.0 \pm 9.0 \mathrm{~mm} \mathrm{Hg}$ for the 18 patients in the trabeculectomy group at the time of reoperation for glaucoma ( $\mathrm{p}=.11$, Student t-test). The IOP levels were also compared between the 12 patients in the tube group and 11 patients in the trabeculectomy group who failed because of inadequate IOP reduction but did not undergo additional glaucoma surgery during 5 years of follow-up. In this patient subgroup, the IOP (mean \pm SD) was $23.0 \pm 5.1$ $\mathrm{mm} \mathrm{Hg}$ in the tube group and $20.1 \pm 2.6$ in the trabeculectomy group $(\mathrm{p}=.11$, Student $\mathrm{t}$ test). The mean IOP prior to reoperation for glaucoma was similar in the tube and trabeculectomy groups, and no significant difference was seen between treatment groups in mean IOP among patients who failed because of inadequate IOP reduction but did not undergo additional glaucoma surgery.

\section{Visual Acuity}

Table 7 and Figure 5 show VA results. Significant decreases in Snellen VA and ETDRS VA were observed in both treatment groups during 5 years of follow-up. Among patients who completed 5-year follow-up visits, logMAR Snellen VA (mean \pm SD) decreased $.38 \pm .72$ units from baseline ( $<.001$, paired t-test) and ETDRS VA (mean \pm SD) was reduced by 15 \pm 26 letters from baseline ( $\mathrm{p}=.001$, paired $\mathrm{t}$-test $)$ in the tube group. In the trabeculectomy group, $\operatorname{logMAR}$ Snellen VA (mean $\pm \mathrm{SD}$ ) decreased $.34 \pm .60$ units $(\mathrm{p}<.001$, paired t-test) and ETDRS VA (mean \pm SD) declined $14 \pm 25$ letters $(\mathrm{p}=.001$, paired t-test) from baseline to the 5-year follow-up visit. No significant differences in Snellen VA ( $\mathrm{p}=.15$, Student ttest) or ETDRS VA ( $p=.068$, Student t-test) were seen between the tube and trabeculectomy group at 5 years. The changes in Snellen VA $(p=.73$, Student t-test $)$ and ETDRS VA $(\mathrm{p}=.83$, Student $\mathrm{t}$-test $)$ from baseline were also similar between treatment groups in patients who completed 5 years of follow-up. ETDRS VA was not measured at the 
5-year follow-up visit in 32 patients in the tube group and 35 patients in the trabeculectomy group. Snellen VA was not assessed at the 5-year visit in 2 patients in the tube group, but 1 of these patients was determined to have lost more than 2 Snellen lines of vision based on change in ETDRS VA.

The rate of loss of 2 or more lines of Snellen VA was similar in the tube and trabeculectomy groups. At 5 years, 31 (46\%) patients in the tube group and 33 (43\%) patients in the trabeculectomy group had lost 2 or more Snellen lines from baseline $(\mathrm{p}=.93$, chi-square test). The distribution of change in Snellen VA from baseline to 5 years in each treatment group is shown in Figure 5. The examining clinician was asked to provide an explanation for reduction of 2 or more lines of Snellen VA from baseline. The most frequent causes of vision loss after 5 years of follow-up were glaucoma in 12 patients in the tube group and 14 patients in the trabeculectomy group, macular disease in 5 patients in the tube group and 5 patients in the trabeculectomy group, and cataract in 2 patients in the tube group and 3 patients in the trabeculectomy group. Other miscellaneous causes for reduced vision in 10 patients in the tube group included corneal edema, diabetic retinopathy, and retinal detachment. Other causes of vision loss in 16 patients in the trabeculectomy group included corneal edema, suprachoroidal hemorrhage, diabetic retinopathy, dislocated intraocular lens, posterior capsular opacification, and endophthalmitis. The reason for decreased vision was unknown in 5 patients in the tube group and 2 patients in the trabeculectomy group.

\section{DISCUSSION}

The TVT Study is a multicenter clinical trial that prospectively enrolled patients with medically uncontrolled glaucoma who had previous cataract extraction with intraocular lens implantation and/or failed filtering surgery and randomized them to surgical treatment with a $350-\mathrm{mm}^{2}$ Baerveldt glaucoma implant or a trabeculectomy with MMC. Patients who underwent tube shunt surgery had a higher success rate compared to trabeculectomy during 5 years of follow-up in the study. At 5 years, the cumulative probability of failure was $29.8 \%$ in the tube group and $46.9 \%$ in the trabeculectomy group. Previously reported data identified a higher failure rate for trabeculectomy with MMC at 1 year and 3 years. ${ }^{11,12}$ The TVT Study shows a persistent treatment benefit of tube shunt surgery over trabeculectomy through 5 years of follow-up in this patient group.

The trabeculectomy failure rate in the TVT Study was comparable to other studies, ${ }^{10,13-23}$ but the failure rate of tube shunt surgery was lower than prior reports. ${ }^{24-33}$ Based upon a systematic review of the published ophthalmic literature, a panel of glaucoma specialists recently concluded that the rates of failure of trabeculectomy and tube shunts are similar and average approximately $10 \%$ per year. ${ }^{33}$ The failure rates of trabeculectomy with MMC in the TVT Study (13.5\% at 1 year, ${ }^{11} 30.7 \%$ at 3 years, ${ }^{12}$ and $46.9 \%$ at 5 years) and trabeculectomy with 5-fluorouracil in the Fluorouracil Filtering Surgery Study (FFSS) (16\% at 1 year, ${ }^{13} 29 \%$ at 3 years, ${ }^{14}$ and $51 \%$ at 5 years ${ }^{10}$ ) were consistent with this estimate, and both are multicenter randomized clinical trials that recruited patients with previous cataract or glaucoma surgery and employed similar success/failure criteria. In contrast, the failure rate of tube shunt surgery averaged about 5\% per year in the TVT Study (3.9\% at 1 year, ${ }^{11}$ $15.1 \%$ at 3 years, ${ }^{12}$ and $29.8 \%$ at 5 years). This more favorable result relative to previous 
reports may relate to differences in study populations, refinements in surgical technique, and/or variations in the definition of failure/success. The TVT Study enrolled eyes at lower risk of surgical failure than have historically undergone tube shunt surgery (e.g. eyes with only prior clear cornea cataract surgery), and it excluded several secondary glaucomas with poorer surgical prognoses (e.g. neovascular glaucoma) that were included in other case series of tube shunts.

Both tube shunt surgery and trabeculectomy with MMC were effective in lowering IOP. Placement of a Baerveldt glaucoma implant produced a $41.4 \%$ reduction in IOP, and trabeculectomy with MMC achieved a $49.5 \%$ decrease in IOP in patients who completed 5 years of follow-up. These results are comparable with previous studies of similar patient groups that reported IOP reduction ranging from $46.4 \%$ to $58.3 \%$ for tube shunt surgery 25,31 and $38.6 \%$ to $61.4 \%$ for trabeculectomy with an adjunctive antifibrotic agent. ${ }^{14,17-19,21-23}$ Glaucoma specialists have suggested that low IOP levels cannot generally be achieved with tube shunts, and the IOP typically settles in the high teens postoperatively. ${ }^{33}$ However, the TVT Study found a mean IOP of $14.4 \mathrm{~mm} \mathrm{Hg}$ in the tube group at 5 years, and $63.9 \%$ had IOP of $14 \mathrm{~mm} \mathrm{Hg}$ or less.

Treatment success was subdivided into complete and qualified successes, based on the use of supplemental medical therapy. Although the overall success rate was higher for the tube group after 5 years, the rates of complete success were not significantly different between treatment groups. This is consistent with the observed similar use of supplemental glaucoma medications by both the tube and trabeculectomy groups at 5 years. The trabeculectomy group had a progressive increase in adjunctive medical therapy during 5 years of follow-up, while the use of glaucoma medications remained relatively constant in the tube group.

The ideal measure of success for any glaucoma therapy is the prevention of further glaucomatous optic nerve damage with preservation of visual function. We recognize that treatment success for individual patients cannot be defined by an arbitrary IOP level, because individuals vary in their susceptibility to the damaging effect of IOP. Nevertheless, IOP lowering remains the primary goal of all current glaucoma therapy and no other surrogate measure better reflects therapeutic success for this disease at the present time. The outcome criteria for the TVT Study were developed a priori, and our definitions of success and failure are similar to previous studies involving the surgical treatment of glaucoma which facilitates comparison with other published results. ${ }^{15-32,34-38}$

The results of several recent multicenter randomized clinical trials have suggested that IOP of $21 \mathrm{~mm} \mathrm{Hg}$ or less may not be adequate to prevent glaucomatous progression in many patients. ${ }^{39-41}$ In order to determine if the TVT Study results changed if more stringent IOP criteria were applied to define success, several post hoc analyses were performed using alternative outcome criteria. Higher failure rates in the trabeculectomy group compared with the tube group were still seen when the upper IOP level defining success was reduced from $21 \mathrm{~mm} \mathrm{Hg}$ to $17 \mathrm{~mm} \mathrm{Hg}$ and $14 \mathrm{~mm} \mathrm{Hg}$. Because the differences in treatment outcomes were present using a broad range of IOP success criteria, the study results seem applicable to patients with early or advanced glaucomatous damage. 
While the overall failure rate was higher in the trabeculectomy group compared with the tube group, the reasons for failure were distributed similarly between treatment groups. Inadequate IOP reduction was the most common reason for failure in both treatment groups. Failure because of persistent hypotony occurred more frequently in the trabeculectomy group than the tube group. It has been argued that hypotony may be an acceptable outcome of glaucoma surgery if it is not associated with vision loss. ${ }^{42}$ It is noteworthy that the vast majority of patients who failed because of persistent hypotony in the TVT Study also had associated vision loss, and the study results did not significantly change when the 3 patients with hypotony and stable vision were reclassified as successes instead of failures. Several baseline factors were examined as possible risk factors for treatment failure, and only treatment assignment predicted treatment outcome.

The rate of reoperation for glaucoma was higher in the trabeculectomy group relative to the tube group. Patients who fail trabeculectomy and need additional glaucoma surgery will generally undergo repeat trabeculectomy or placement of a tube shunt. However, additional glaucoma surgery in eyes that have failed tube shunt surgery is more complex and usually involves placement of a second tube shunt or cyclodestruction. ${ }^{34,35}$ Because investigators in the TVT Study were not masked to the treatment assignment and the decision to reoperate was left to the surgeon's discretion, a potential for bias existed in the decision to reoperate for glaucoma. We explored for the possibility that surgeons may have had a higher threshold to perform additional glaucoma surgery in the tube group than the trabeculectomy group. No significant difference in mean IOP at the time of failure was seen between treatment groups in patients who had a reoperation for glaucoma, or in patients who failed because of inadequate IOP reduction but did not have additional glaucoma surgery. These observations suggest that no selection bias was present for glaucoma reoperation.

Reduction of VA occurred in both treatment groups during 5 years of follow-up. Snellen and ETDRS VA were similar in the tube and trabeculectomy groups at 5 years, and no significant differences in the rates and reasons for vision loss were present between treatment groups. Vision loss of 2 or more Snellen lines was most frequently attributed to glaucoma by the examining clinicians. The high rate of vision loss from glaucoma in the TVT Study may relate to the advanced stage of disease of many patients, with an average mean deviation on Humphrey visual field testing of -15.9 decibels in the overall study group at baseline. Some of the causes of vision loss, such as diabetic retinopathy and posterior capsular opacification, were not directly attributable to the surgical procedures under study.

Wilson and associates compared the Ahmed glaucoma valve implant (New World Medical, Inc., Rancho Cucamonga, California) to trabeculectomy with or without an antifibrotic agent in a randomized clinical trial involving 117 patients. ${ }^{37}$ Lower mean IOP was observed in the trabeculectomy group, and the Ahmed group had a greater adjunctive medication requirement with a mean follow-up of 9.7 months. The cumulative probabilities of success (IOP $<21 \mathrm{~mm} \mathrm{Hg}$ and at least 15\% reduction in IOP from preoperative level) were similar between the two treatment groups. This study was performed in Saudi Arabia and Sri Lanka, and included patients with all glaucoma types and some eyes that had undergone previous ocular surgery. A follow-up study continued enrollment in Sri Lanka to a total of 123 
patients with primary open-angle glaucoma and angle-closure glaucoma without previous ocular surgery. ${ }^{38}$ With a mean follow-up of 31 months, mean IOPs and success rates were comparable between the trabeculectomy and Ahmed groups. The difference in study results between the TVT Study and the studies by Wilson and colleagues may relate to differences in study populations, success and failure criteria, and retention during follow-up. The TVT

Study also used the Baerveldt implant for patients randomized to the tube group, and the end plate of this implant has a larger surface area than the Ahmed implant. There is evidence suggesting that implants with larger plates produce greater pressure reduction. ${ }^{27,33,43}$

There are several limitations to the TVT Study. The study population was restricted to patients who had undergone previous cataract extraction with intraocular lens implantation and/or trabeculectomy, and several patient types were ineligible for enrollment. Results of the TVT Study cannot be directly applied to dissimilar patient groups. All patients randomized to the tube group received a $350-\mathrm{mm}^{2}$ Baerveldt glaucoma implant, and the study results should not be generalized to different implant types. A trend toward use of a lower dosage of MMC has developed since the TVT Study was initiated, ${ }^{44}$ and it is unclear whether the higher MMC dosage in this study may have been associated with a higher rate of hypotony and/or a lower rate of trabeculectomy failure due to bleb fibrosis. While aspects of both surgical procedures were standardized (e.g. quadrant of tube shunt placement, dosage of MMC), some variation in surgical technique occurred because surgeons were allowed some latitude to perform the operations in a manner with which he or she was comfortable. A subgroup of patients enrolled in the TVT Study (i.e., those with a history of prior trabeculectomy with MMC) had already failed one treatment arm of the study, and potentially could have introduced bias in favor of the tube group. We felt that the study question of how one surgical procedure compares to the other was clinically relevant in eyes that had failed a MMC trabeculectomy, and a separate stratum (stratum 4) was created for these eyes to facilitate data analysis and address concerns about possible bias. No significant differences in treatment efficacy were observed between strata.

The 5-year results of the TVT Study provide further evidence that the role of tube shunts have appropriately been expanding beyond the surgical management of refractory glaucomas. This study enrolled patients at lower risk of surgical failure than have traditionally had tube shunt surgery. In eyes with previous cataract and/or glaucoma surgery, the TVT Study found that tube shunt surgery had a higher success rate compared to trabeculectomy with MMC during 5 years of follow-up. The two surgical procedures were associated with similar IOP reduction and use of supplemental medical therapy at 5 years. The rate of reoperation for glaucoma was higher after trabeculectomy with MMC than tube shunt placement. Vision loss occurred at a similar rate after both procedures.

The TVT Study does not demonstrate clear superiority of one glaucoma operation over the other, but indicates that both tube shunt surgery and trabeculectomy with MMC are viable surgical options for treating medically uncontrolled glaucoma in patients with previous cataract extraction or failed filtering surgery. The study results have supported a shift in practice patterns among glaucoma surgeons toward greater use of tube shunts in similar patient groups. When Chen and associates conducted an anonymous survey of members of the American Glaucoma Society and Japanese Glaucoma Society to evaluate use of 
antifibrotic agents and tube shunts in 1996, the vast majority of surgeons favored trabeculectomy with MMC for clinical situations requiring glaucoma surgical intervention. ${ }^{6}$ Desai and colleagues readministered the same survey to the American Glaucoma Society membership in 2008 and found a marked increase in the use of tube shunts, with the greatest practice pattern shift occurring in the management of patients with prior cataract and glaucoma surgery. ${ }^{8}$ In particular, selection of tube shunts as the preferred surgical approach increased from $7 \%$ to $46 \%$ in eyes with previous trabeculectomy, and increased from $8 \%$ to $45 \%$ in eyes with prior extracapsular and intracapsular cataract extraction.

Even though randomized clinical trials like the TVT Study offer the highest level of evidence based medicine, other factors must be considered when selecting a glaucoma surgical procedure. The surgeon's skill and experience with both operations, the patient's willingness to undergo repeat glaucoma surgery, and the surgeon's planned surgical approach should failure occur are other important factors in surgical decision making. The benefit of tube shunt surgery and trabeculectomy with MMC in reducing IOP must be interpreted in the context of their adverse events. Our companion paper describes the postoperative complications encountered in the TVT Study during 5 years of follow-up and the management of these complications.

\section{Supplementary Material}

Refer to Web version on PubMed Central for supplementary material.

\section{Acknowledgments}

A. The study was supported by research grants from Pfizer, Inc., New York, New York, Abbott Medical Optics, Santa Ana, California, the National Eye Institute (grant EY014801), National Institutes of Health, Bethesda, Maryland, and Research to Prevent Blindness, Inc., New York, New York.

B. The following investigators have disclosed a financial interest in the manufacturer of the Baerveldt glaucoma implant: Keith Barton, M.D.: grant support. James Brandt, M.D.: advisory board. William Feuer, M.S.: grant support. Joyce Schiffman, M.S.: grant support.

C. Involved in design and conduct of study (S.J.G., J.C.S., W.J.F., L.W.H., J.D.B., D.L.B.); collection, management, analysis, and interpretation of data (S.J.G., J.C.S., W.J.F., L.W.H., J.D.B., D.L.B.); and preparation, review, and approval of the manuscript (S.J.G., J.C.S., W.J.F., L.W.H., J.D.B., D.L.B.).

D. The study was approved by the Institutional Review Board at each Clinical Center. Written informed consent was obtained from all subjects for both the treatment and participation in the research. The study adhered to the Declaration of Helsinki and the Health Insurance Portability and Accountability Act (HIPAA). This study is registered in http://www.clinicaltrials.gov (NCT00306852).

\section{References}

1. Minckler D, Mosaed S, Dustin L, Francis B. Trabectome Study Group. Trabectome (trabeculectomy-internal approach): Additional experience and extended follow-up. Trans Am Ophthalmol Soc. 2008; 106:149-159. [PubMed: 19277230]

2. Lewis RA, von Wolff K, Tetz M, et al. Canaloplasty: Circumferential viscodilation and tensioning of Schlemm canal using a flexible microcatheter for the treatment of open-angle glaucoma in adults: Two year interim clinical study. J Cataract Refract Surg. 2009; 35(5):814-824. [PubMed: 19393879]

3. Melamed S, Ben Simon GJ, Goldenfeld M, Simon G. Efficacy and safety of gold micro shunt implantation to the supraciliary space in patients with glaucoma: A pilot study. Arch Ophthalmol. 2009; 127(3):264-269. [PubMed: 19273788] 
4. Samuelson TW, Katz LJ, Wells JM, Duh YJ, Giamporcaro JE. US iStent Study Group. Randomized evaluation of the trabecular micro-bypass stent with phacoemulsification in patients with glaucoma and cataract. Ophthalmology. 2011; 118(3):459-467. [PubMed: 20828829]

5. Ramulu PY, Corcoran KJ, Corcoran SL, Robin AL. Utilization of various glaucoma surgeries and procedures in Medicare beneficiaries from 1995 to 2004. Ophthalmology. 2007; 114(12):22652270. [PubMed: 17466376]

6. Chen PP, Yamamoto T, Sawada A, Parrish RK, Kitazawa Y. Use of antifibrosis agents and glaucoma drainage devices in the American and Japanese Glaucoma Societies. J Glaucoma. 1997; 6(3):192-196. [PubMed: 9211144]

7. Joshi AB, Parrish RK, Feuer WF. 2002 Survey of the American Glaucoma Society. Practice preferences for glaucoma surgery and antifibrotic use. J Glaucoma. 2005; 14(2):172-174. [PubMed: 15741822]

8. Desai MA, Gedde SJ, Feuer WJ, Whi W, Chen PP, Parrish RK. Practice preferences for glaucoma surgery: A survey of the American Glaucoma Society in 2008. Ophthalmic Surg Lasers Imaging. 2011; 42(3):202-208. [PubMed: 21563745]

9. Gedde SJ, Schiffman JC, Feuer WJ, et al. The Tube Versus Trabeculectomy Study: Design and baseline characteristics of study patients. Am J Ophthalmol. 2005; 140(2):275-287. [PubMed: 16086949]

10. The Fluorouracil Filtering Surgery Study Group. Five-year follow-up of the fluorouracil filtering surgery study. Am J Ophthalmol. 1996; 121(4):349-366. [PubMed: 8604728]

11. Gedde SJ, Schiffman JC, Feuer WJ, et al. Treatment outcomes in the Tube Versus Trabeculectomy Study after one year of follow-up. Am J Ophthalmol. 2007; 143(1):9-22. [PubMed: 17083910]

12. Gedde SJ, Schiffman JC, Feuer WJ, et al. Three-year follow-up of the Tube Versus Trabeculectomy Study. Am J Ophthalmol. 2009; 148(5):670-84. [PubMed: 19674729]

13. The Fluorouracil Filtering Surgery Study Group. Fluorouracil filtering surgery study one-year follow-up. Am J Ophthalmol. 1989; 108(6):625-635. [PubMed: 2688428]

14. The Fluorouracil Filtering Surgery Study Group. Three-year follow-up of the fluorouracil filtering surgery study. Am J Ophthalmol. 1993; 115(1):82-92. [PubMed: 8420383]

15. Heuer DK, Parrish RK, Gressel MG, Hodapp E, Palmberg PF, Anderson DR. 5-fluorouracil and glaucoma filtering surgery: II. A pilot study. Ophthalmology. 1984; 91(4):384-394. [PubMed: 6201793]

16. Heuer DK, Parrish RK, Gressel MG, et al. 5-fluorouracil and glaucoma filtering surgery: III. Intermediate follow-up of a pilot study. Ophthalmology. 1986; 93(12):1537-1546. [PubMed: 2433656]

17. Weinreb RN. Adjusting the dose of 5-fluorouracil after filtration surgery to minimize side effects. Ophthalmology. 1987; 94(5):564-570. [PubMed: 2439972]

18. Palmer SS. Mitomycin as adjunct chemotherapy with trabeculectomy. Ophthalmology. 1991; 98(3):317-321. [PubMed: 2023752]

19. Prata JA, Minckler DS, Baerveldt G, Lee PP, LaBree L, Heuer DK. Trabeculectomy in pseudophakic patients: postoperative 5-fluorouracil versus intraoperative mitomycin C antiproliferative therapy. Ophthalmic Surg. 1995; 26(1):73-77. [PubMed: 7746631]

20. Chen CW, Huang HT, Bair JS, Lee CC. Trabeculectomy with simultaneous topical application of mitomycin-C in refractory glaucoma. J Ocular Pharmacol. 1990; 6(3):175-182.

21. Singh J, O'Brien C, Chawla HB. Success rate and complications of intraoperative $0.2 \mathrm{mg} / \mathrm{ml}$ mitomycin C in trabeculectomy surgery. Eye. 1995; 9(4):460-466. [PubMed: 7498567]

22. Andreanos D, Georgopoulos GT, Vergados J, Papaconstantinou D, Liokis N, Theodossiadis P. Clinical evaluation of the effect of mitomycin-C in re-operation for primary open angle glaucoma. Eur J Ophthalmol. 1997; 7(1):49-54. [PubMed: 9101195]

23. You YA, Gu YS, Fang CT, Ma XQ. Long-term effects of simultaneous and subscleral mitomycin C application in repeat trabeculectomy. J Glaucoma. 2002; 11(2):110-118. [PubMed: 11912358]

24. Minckler DS, Heuer DK, Hasty B, Baerveldt G, Cutting RC, Barlow WE. Clinical experience with the single-plate Molteno implant in complicated glaucomas. Ophthalmology. 1988; 95(9):11811188. [PubMed: 3211496] 
25. Freedman J, Rubin B. Molteno implants as a treatment for refractory glaucoma in black patients. Arch Ophthalmol. 1991; 109(10):1417-1420. [PubMed: 1929932]

26. Lloyd MA, Sedlak T, Heuer DK, et al. Clinical experience with the single plate Molteno implant in complicated glaucomas. Update of a pilot study. Ophthalmology. 1992; 99(5):679-687. [PubMed: 1594211]

27. Heuer DK, Lloyd MA, Abrams DA, et al. Which is better? One or two? A randomized clinical trial of single-plate versus double-plate Molteno implantation for glaucomas in aphakia and pseudphakia. Ophthalmology. 1992; 99(10):1512-19. [PubMed: 1454316]

28. Hodkin MJ, Goldblatt WS, Burgoyne CF, Ball SF, Insler MS. Early clinical experience with the Baerveldt implant in complicated glaucomas. Am J Ophthalmol. 1995; 120(1):32-40. [PubMed: 7611327]

29. Mills RP, Reynolds A, Emond MJ, Barlow WE, Leen MM. Long-term survival of Molteno glaucoma drainage devices. Ophthalmology. 1996; 103(2):299-305. [PubMed: 8594518]

30. Huang MC, Netland PA, Coleman AL, Siegner SW, Moster MR, Hill RA. Intermediate-term clinical experience with the Ahmed glaucoma valve implant. Am J Ophthalmol. 1999; 127(1):2733. [PubMed: 9932995]

31. Broadway DC, Iester M, Schulzer M, Douglas GR. Survival analysis for success for Molteno tube implants. Br J Ophthalmol. 2001; 85(6):689-895. [PubMed: 11371490]

32. Roy S, Ravinet E, Mermoud A. Baerveldt implant in refractory glaucoma: Long-term results and factors influencing outcomes. Int Ophthalmol. 2001; 24(2):93-100. [PubMed: 12201350]

33. Minckler DS, Francis BA, Hodapp EA, et al. Aqueous shunts in glaucoma: A report by the American Academcy of Ophthalmology. Ophthalmology. 2008; 115(6):1089-1098. [PubMed: 18519069]

34. Shah AA, WuDunn D, Cantor LB. Shunt revision versus additional tube shunt implantation after failed tube shunt surgery in refractory glaucoma. Am J Ophthalmol. 2000; 129(4):455-460. [PubMed: 10764852]

35. Godfrey DG, Krishna R, Greenfield DS, Budenz DL, Gedde SJ, Scott IU. Implantation of second glaucoma drainage devices after failure of primary devices. Ophthalmic Surg Lasers. 2002; 33(1): 37-43. [PubMed: 11820661]

36. Krishna R, Godfrey DG, Budenz DL, et al. Intermediate-term outcomes of 350- $\mathrm{mm}^{2}$ Baerveldt glaucoma implants. Ophthalmology. 2001; 108(3):621-626. [PubMed: 11237919]

37. Wilson MR, Mendis U, Smith SD, Paliwal A. Ahmed glaucoma valve implant vs. trabeculectomy in the surgical treatment of glaucoma: A randomized clinical trial. Am J Ophthalmol. 2000; 130(3):267-273. [PubMed: 11020403]

38. Wilson MR, Mendis U, Paliwal A, Haynatzka V. Long-term follow-up of primary glaucoma surgery with Ahmed glaucoma valve implant versus trabeculectomy. Am J Ophthalmol. 2003; 136(3):464-470. [PubMed: 12967799]

39. Lichter PR, Musch DC, Gillespie BW, et al. Interim clinical outcomes in the Collaborative Initial Glaucoma Treatment Study comparing initial treatment randomized to medications or surgery. Ophthalmology. 2001; 108(11):1943-1953. [PubMed: 11713061]

40. The AGIS Investigators. The Advanced Glaucoma Intervention Study (AGIS): 7. The relationship between control of intraocular pressure and visual field deterioration. Am J Ophthalmol. 2000; 130(4):429-440. [PubMed: 11024415]

41. Heijl A, Leske MC, Bengtsson B, et al. Reduction of intraocular pressure and glaucoma progression: Results from the Early Manifest Glaucoma Trial. Arch Ophthalmol. 2002; 120(10): 1268-1279. [PubMed: 12365904]

42. Jamil AL, Mills RP. Glaucoma tube or trabeculectomy? That is the question. Am J Ophthalmol. 2007; 143(1):141-142. [PubMed: 17188048]

43. Budenz DL, Barton K, Feuer WJ, et al. Treatment outcomes in the Ahmed Baerveldt Comparison Study after 1 year of follow-up. Ophthalmology. 2011; 118(3):443-452. [PubMed: 20932583]

44. Jones E, Clarke J, Khaw PT. Recent advances in trabeculectomy technique. Curr Opin Ophthalmol. 2005; 16(2):107-113. [PubMed: 15744141] 


\section{Biography}

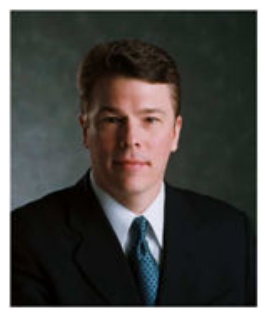

Steven J. Gedde, M.D. is a Professor of Ophthalmology and Residency Program Director at the Bascom Palmer Eye Institute. He is a study chairman in the Tube Versus Trabeculectomy Study and Primary Tube Versus Trabeculectomy Study. His research interests include glaucoma drainage implants, complications of glaucoma surgery, quality of life, and resident education.

\section{APPENDIX}

\section{Participating Centers and Committees in the Tube Versus Trabeculectomy Study} Clinical Centers

Bascom Palmer Eye Institute, Miller School of Medicine, University of Miami (Miami, Florida): Principal Investigator: Steven Gedde, M.D.; Coinvestigators: Douglas Anderson, M.D., Michael Banitt, M.D., Donald Budenz, M.D., M.P.H., Madeline Del Calvo, Francisco Fantes, M.D., Fouad El Sayyad, M.D., David Greenfield, M.D., Jessica Hochberg, Elizabeth Hodapp, M.D., Anna Junk, M.D., Richard Lee, M.D., Ph.D., Alexia Marcellino, Paul Palmberg, M.D. Ph.D., Richard Parrish II, M.D., Sarah Wellik, M.D.

Duke University (Durham, North Carolina): Principal Investigator: Leon Herndon, M.D.; Coinvestigators: Pratap Challa, M.D., Cecile Santiago-Turla, M.D.

Indiana University (Indianapolis, Indiana): Principal Investigator: Darrell WuDunn, M.D., Ph.D.

Loyola University (Maywood, Illinois): Principal Investigator: Geoffrey Emerick, M.D.

Medical College of Wisconsin (Milwaukee, Wisconsin): Principal Investigator: Dale Heuer, M.D.

Medical University of South Carolina (Charleston, South Carolina): Principal Investigator: Alexander Kent, M.D.; Coinvestigators: Carol Bradham, Lisa Langdale. Moorfields Eye Hospital (London, England): Principal Investigator: Keith Barton, M.D.; Coinvestigator: Francesca Amalfitano, Renata Puertas, M.D., Poornima Rai, M.D.

New York Eye and Ear Infirmary (New York, New York): Principal Investigator: Paul Sidoti, M.D.; Coinvestigators: Amy Gedal, James Luayon, Roma Ovase, Katy Tai 
Scripps Clinic (La Jolla, California): Principal Investigator: Quang Nguyen, M.D.;

Coinvestigator: Neva Miller

St. Louis University (St. Louis Missouri): Principal Investigator: Steven Shields, M.D.; Coinvestigators: Kevin Anderson, Frank Moya, M.D.

University of California, Davis (Sacramento, California): Principal Investigator: James Brandt, M.D.; Coinvestigator: Michele Lim, M.D., Marilyn Sponzo.

University of Florida (Gainesville, Florida): Principal Investigator: Mark Sherwood, M.D.; Coinvestigator: Revonda Burke

University of Oklahoma (Oklahoma City, Oklahoma): Principal Investigator: Gregory Skuta, M.D.; Coinvestigators: Jason Jobson, Mahmoud Khaimi, M.D., Lisa Ogilbee, Adam Reynolds, M.D., Steven Sarkisian, M.D.

University of Southern California (Los Angeles, California): Principal Investigator: Rohit Varma, M.D., M.P.H.; Coinvestigators: Brian Francis, M.D., Frances Walonker

University of Texas Houston (Houston, Texas): Principal Investigator: Robert Feldman, M.D.; Coinvestigators: Laura Baker, Nicholas Bell, JoLene Carranza, Athena Espinoza

University of Virginia (Charlottesville, Virginia): Principal Investigator: Bruce Prum, M.D.; Coinvestigator: Janis Beall

University of Wisconsin (Madison, Wisconsin): Principal Investigator: Todd Perkins, M.D.; Coinvestigators: Paul Kaufman, M.D., Tracy Perkins, Barbara Soderling.

Statistical Coordinating Center, Bascom Palmer Eye Institute, Miller School of Medicine, University of Miami (Miami, Florida): William Feuer, M.S., Luz Londono, Joyce Schiffman, M.S., Wei Shi, M.S.

Safety and Data Monitoring Committee: Philip Chen, M.D., William Feuer, M.S., Joyce Schiffman, M.S., Kuldev Singh, M.D., M.P.H., George Spaeth, M.D., Martha Wright, M.D.

Steering Committee: Keith Barton, M.D., James Brandt, M.D., Geoffrey Emerick, M.D., Robert Feldman, M.D., Steven Gedde, M.D., Leon Herndon, M.D., Dale Heuer, M.D., Alexander Kent, M.D., Quang Nguyen, M.D., Richard Parrish II, M.D., Todd Perkins, M.D., Bruce Prum, M.D., Mark Sherwood, M.D., Steven Shields, M.D., Paul Sidoti, M.D., Gregory Skuta, M.D., Rohit Varma, M.D., M.P.H., Darrell WuDunn, M.D., Ph.D.

Study Chairmen: Steven Gedde, M.D., Dale Heuer M.D., Richard Parrish II, M.D. 


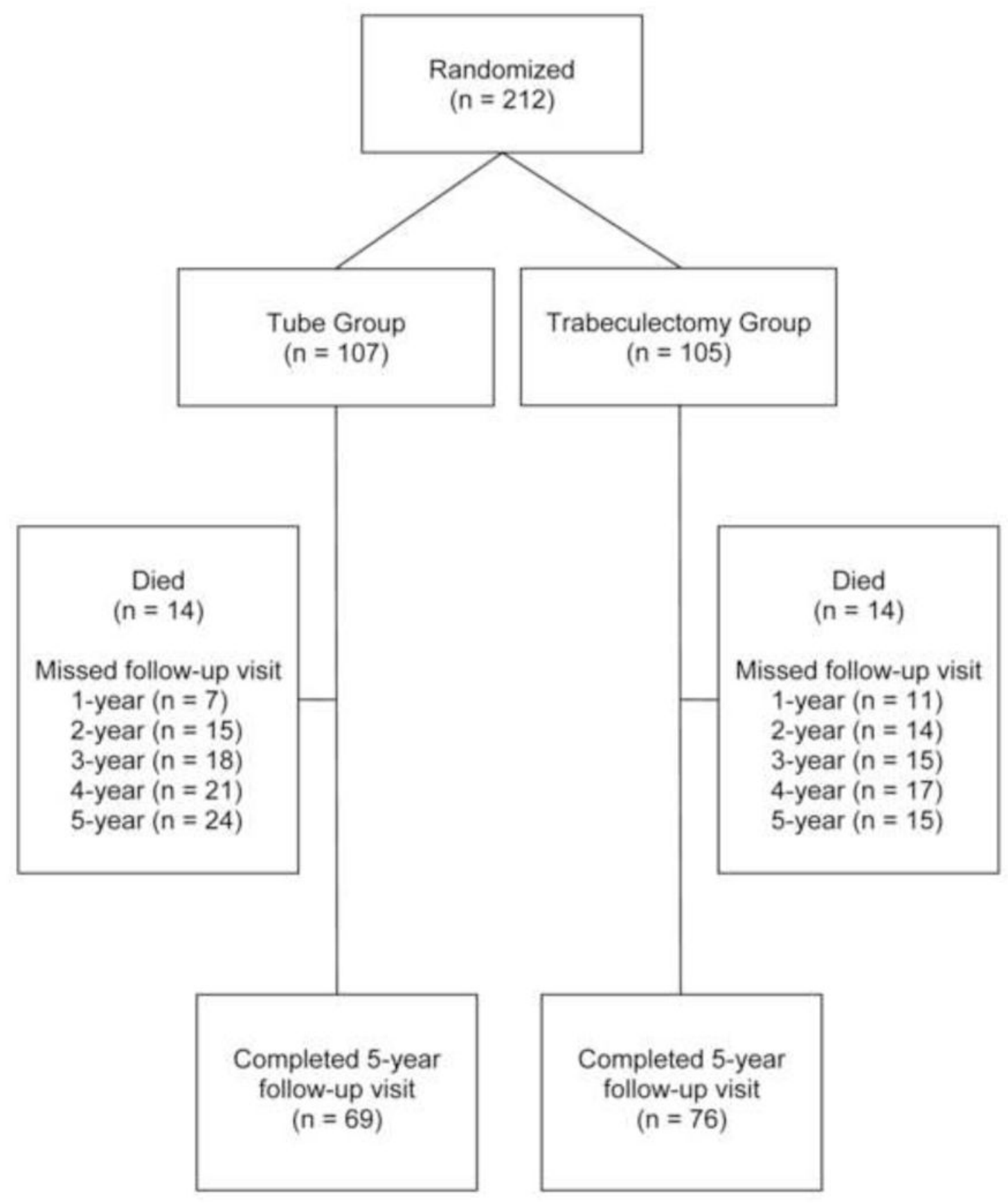

Figure 1.

Flowchart of patient progress in the Tube Versus Trabeculectomy Study. 


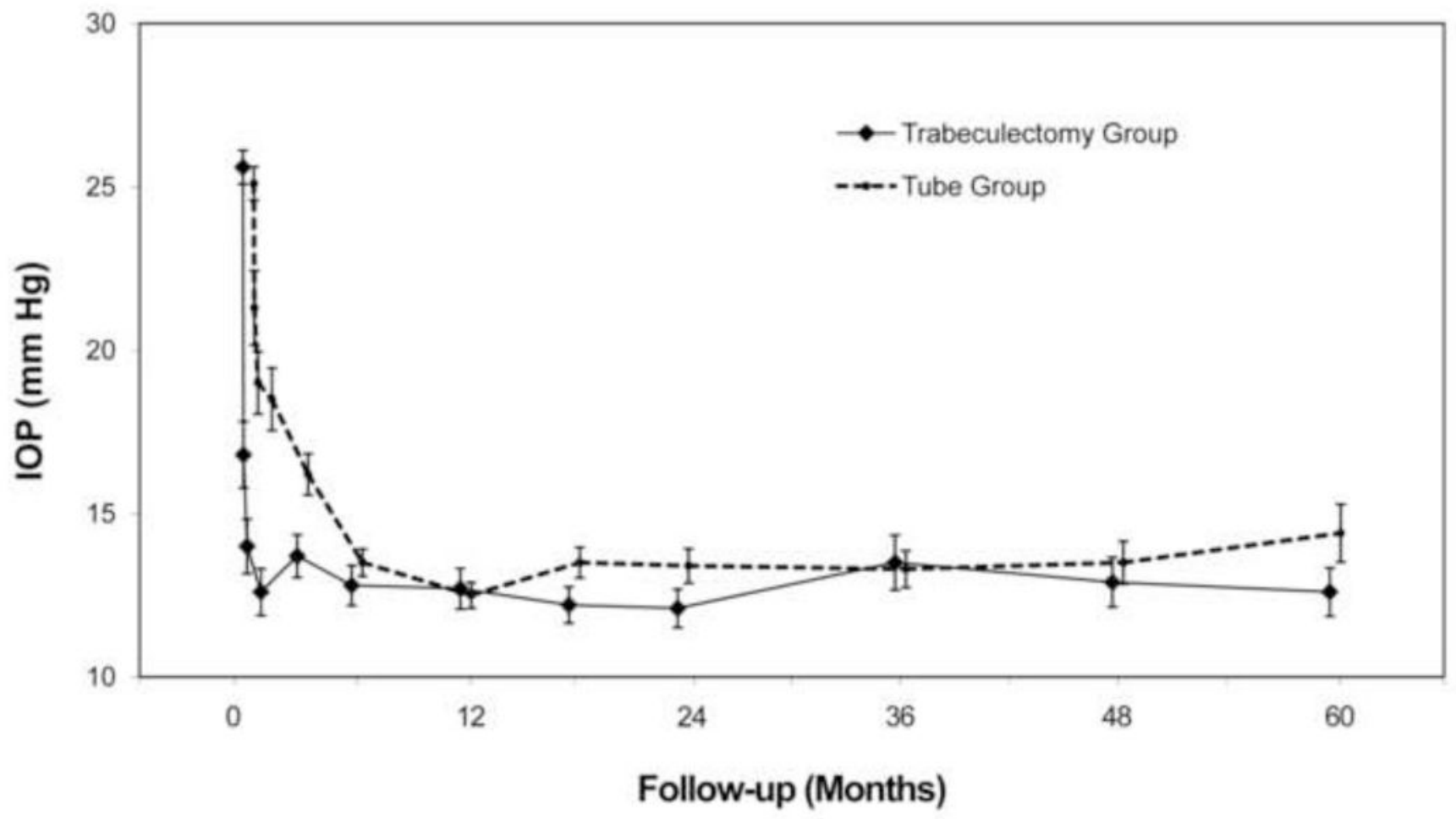

Figure 2.

Intraocular pressure (IOP) at baseline and follow-up in the Tube Versus Trabeculectomy Study. Data are presented as mean \pm standard error of the mean and are censored after a reoperation for glaucoma. 


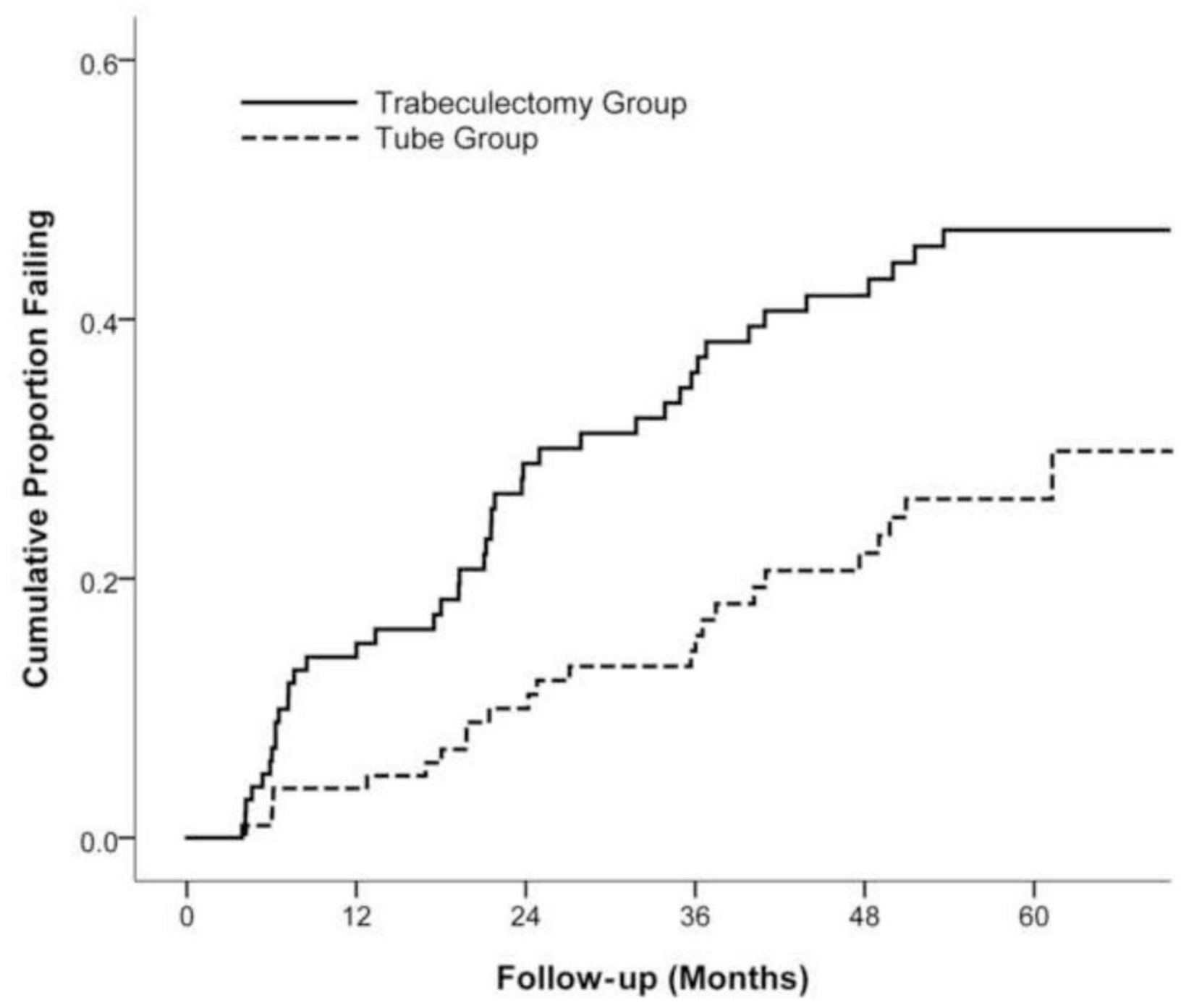

Figure 3.

Kaplan-Meier plots of the probability of failure in the Tube Versus Trabeculectomy Study. 

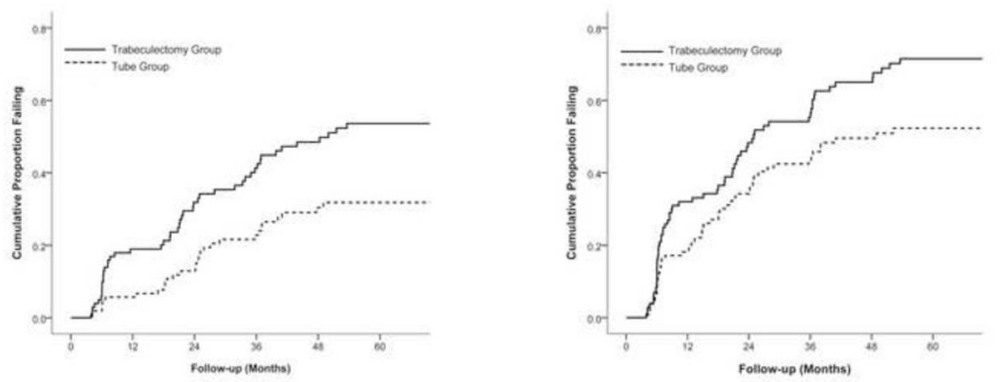

Figure 4.

Kaplan-Meier plots of the cumulative probability of failure in the Tube Versus

Trabeculectomy Study defining inadequate intraocular (IOP) reduction as IOP > $17 \mathrm{~mm} \mathrm{Hg}$ or not reduced by $20 \%$ below baseline (left) or IOP > $14 \mathrm{~mm} \mathrm{Hg}$ (right). Inadequate IOP reduction criteria must have been present on 2 consecutive visits after 3 months to qualify as failure. Patients with persistent hypotony, reoperation for glaucoma, and loss of light perception vision are classified as failures. 


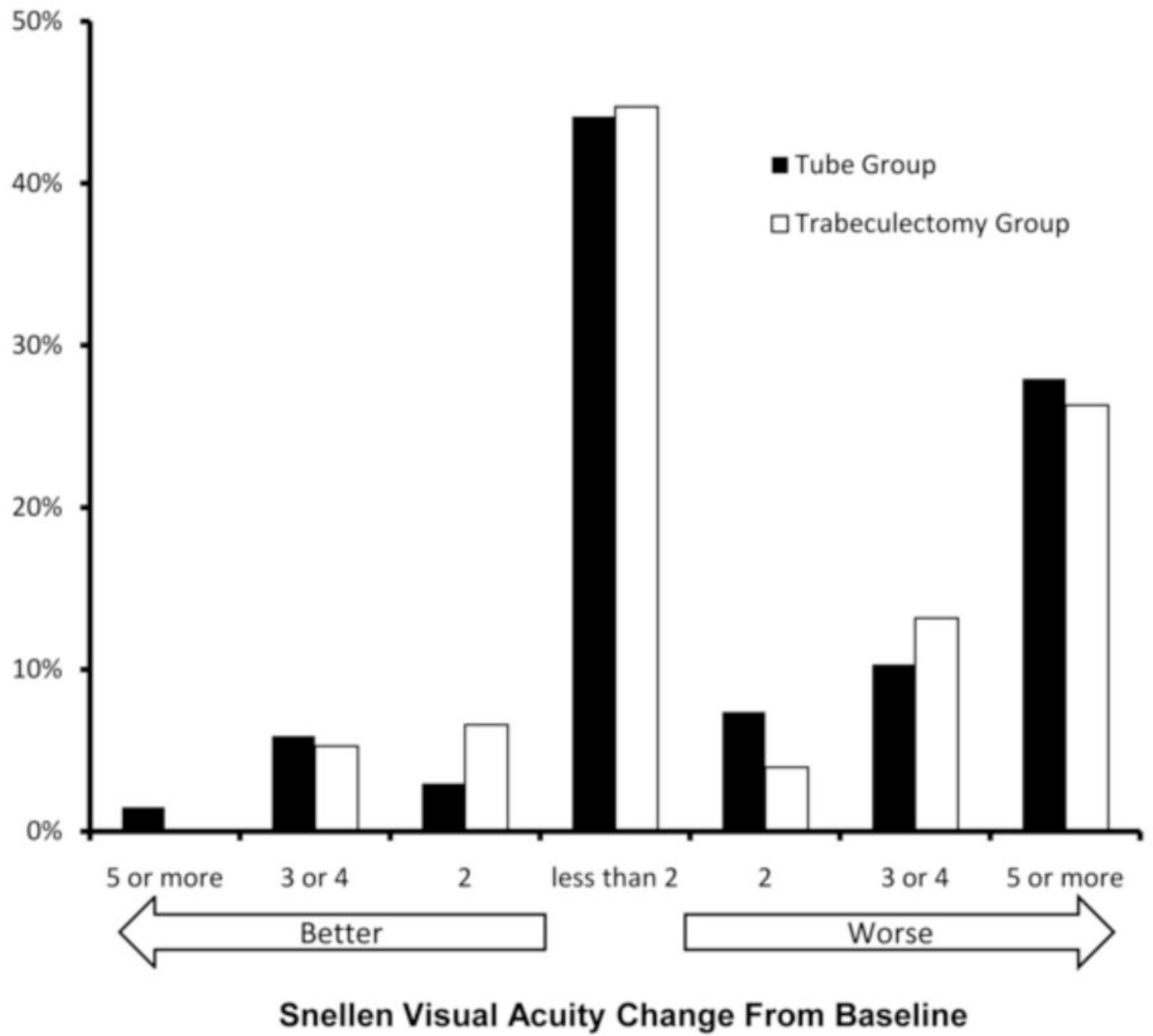

Figure 5.

Distribution of change in visual acuity from baseline to the 5-year follow-up visit in the Tube Versus Trabeculectomy Study. 
Table 1

Baseline Characteristics of Tube Versus Trabeculectomy Study Patients

\begin{tabular}{|c|c|c|c|}
\hline & Tube Group $(\mathrm{n}=107)$ & Trabeculectomy Group $(n=105)$ & P-value \\
\hline Age (years), mean $\pm \mathrm{SD}$ & $70.9 \pm 11.0$ & $71.1 \pm 9.9$ & $.89^{a}$ \\
\hline Gender, $\mathrm{n}(\%)$ & & & $.055^{b}$ \\
\hline Male & $43(40)$ & $57(54)$ & \\
\hline Female & $64(60)$ & $48(46)$ & \\
\hline Race, $\mathrm{n}(\%)$ & & & $.53^{c}$ \\
\hline White & $52(49)$ & $43(41)$ & \\
\hline Black & $40(37)$ & $42(40)$ & \\
\hline Hispanic & $12(11)$ & $18(17)$ & \\
\hline Other & $3(3)$ & $2(2)$ & \\
\hline Diabetes mellitus, n (\%) & $31(29)$ & $36(34)$ & $.49^{b}$ \\
\hline Hypertension, n (\%) & $61(57)$ & $63(60)$ & $.76^{b}$ \\
\hline $\mathrm{IOP}(\mathrm{mm} \mathrm{Hg})$, mean $\pm \mathrm{SD}$ & $25.1 \pm 5.3$ & $25.6 \pm 5.3$ & $.56^{a}$ \\
\hline Glaucoma medications, mean $\pm \mathrm{SD}$ & $3.2 \pm 1.1$ & $3.0 \pm 1.2$ & $.17^{a}$ \\
\hline Diagnosis, n (\%) & & & $.057^{c}$ \\
\hline POAG & $88(82)$ & $84(80)$ & \\
\hline CACG & $7(7)$ & $11(10)$ & \\
\hline PXFG & $7(7)$ & $1(1)$ & \\
\hline PG & $1(1)$ & $0(0)$ & \\
\hline Other & $4(4)$ & $9(9)$ & \\
\hline Lens status, n (\%) & & & $.85^{c}$ \\
\hline Phakic & $24(22)$ & $21(20)$ & \\
\hline PCIOL & $80(75)$ & $80(76)$ & \\
\hline ACIOL & $3(3)$ & $4(4)$ & \\
\hline Previous intraocular surgery & & & $.35^{a}$ \\
\hline Mean \pm SD & $1.3 \pm 0.5$ & $1.2 \pm 0.5$ & \\
\hline Range & $1-3$ & $1-4$ & \\
\hline Interval (months), mean $\pm \mathrm{SD}^{e}$ & $54 \pm 50$ & $60 \pm 55$ & $.42^{a}$ \\
\hline ETDRS VA, mean \pm SD & $62.7 \pm 24.1$ & $64.4 \pm 19.6$ & $.56^{a}$ \\
\hline \multicolumn{4}{|l|}{ Snellen VA } \\
\hline Median & $20 / 30$ & $20 / 40$ & $.76^{d}$ \\
\hline Range & 20/17 - HM & $20 / 20-2 / 200$ & \\
\hline
\end{tabular}

Am J Ophthalmol. Author manuscript; available in PMC 2015 June 09. 


\begin{tabular}{|c|c|c|c|}
\hline & Tube Group $(\mathrm{n}=107)$ & Trabeculectomy Group $(n=105)$ & P-value \\
\hline LogMAR mean $\pm \mathrm{SD}$ & $.42 \pm .54$ & $.37 \pm .38$ & $.40^{a}$ \\
\hline \multicolumn{4}{|l|}{ Humphrey visual fields } \\
\hline $\mathrm{MD}$, mean $\pm \mathrm{SD}$ & $-16.0 \pm 10.2$ & $-15.8 \pm 9.6$ & $0.87^{a}$ \\
\hline $\mathrm{PSD}$, mean $\pm \mathrm{SD}$ & $7.1 \pm 3.5$ & $6.9 \pm 3.5$ & $0.73^{a}$ \\
\hline
\end{tabular}

$\mathrm{ACIOL}=$ anterior chamber intraocular lens; $\mathrm{CACG}=$ chronic angle-closure glaucoma; ETDRS $=$ Early Treatment Diabetic Retinopathy Study; $\mathrm{HM}=$ hand motion $; \mathrm{IOP}=$ intraocular pressure $\mathrm{MD}=$ mean deviation; $\mathrm{PCIOL}=$ posterior chamber intraocular lens; $\mathrm{PG}=$ pigmentary glaucoma; $\mathrm{POAG}=$ primary open-angle glaucoma $\mathrm{PSD}=$ pattern standard deviation $; \mathrm{PXFG}=$ pseudoexfoliation glaucoma; $\mathrm{SD}=$ standard deviation; $\mathrm{VA}=$ visual acuity

${ }^{a}$ Student t-test

${ }^{b}$ Chi-square test

${ }^{c}$ Exact permutation chi-square test

${ }^{d}$ Mann-Whitney U test

${ }^{e}$ Interval between last intraocular surgery and surgical treatment in study 
Table 2

Intraocular Pressure and Medical Therapy at Baseline and Follow-up in the Tube Versus Trabeculectomy Study

\begin{tabular}{|c|c|c|c|}
\hline & Tube Group & Trabeculectomy Group & P-value ${ }^{a}$ \\
\hline \multicolumn{4}{|l|}{ Baseline } \\
\hline $\mathrm{IOP}(\mathrm{mm} \mathrm{Hg})$ & $25.1 \pm 5.3$ & $25.6 \pm 5.3$ & .56 \\
\hline Glaucoma medications & $3.2 \pm 1.1$ & $3.0 \pm 1.2$ & .17 \\
\hline $\mathrm{n}$ & 107 & 105 & \\
\hline \multicolumn{4}{|l|}{1 year } \\
\hline $\mathrm{IOP}(\mathrm{mm} \mathrm{Hg})$ & $12.5 \pm 3.9$ & $12.7 \pm 5.8$ & 0.75 \\
\hline Glaucoma medications & $1.3 \pm 1.3$ & $0.5 \pm 0.9$ & $<.001$ \\
\hline $\mathrm{n}$ & 97 & 87 & \\
\hline \multicolumn{4}{|l|}{2 years } \\
\hline $\mathrm{IOP}(\mathrm{mm} \mathrm{Hg})$ & $13.4 \pm 4.8$ & $12.1 \pm 5.0$ & .097 \\
\hline Glaucoma medications & $1.3 \pm 1.3$ & $0.8 \pm 1.2$ & .019 \\
\hline $\mathrm{n}$ & 83 & 72 & \\
\hline \multicolumn{4}{|l|}{3 years } \\
\hline $\mathrm{IOP}(\mathrm{mm} \mathrm{Hg})$ & $13.3 \pm 5.0$ & $13.5 \pm 6.9$ & .83 \\
\hline Glaucoma medications & $1.3 \pm 1.3$ & $1.0 \pm 1.5$ & .31 \\
\hline $\mathrm{n}$ & 78 & 68 & \\
\hline \multicolumn{4}{|l|}{4 years } \\
\hline $\mathrm{IOP}(\mathrm{mm} \mathrm{Hg})$ & $13.5 \pm 5.4$ & $12.9 \pm 6.1$ & .58 \\
\hline Glaucoma medications & $1.4 \pm 1.4$ & $1.2 \pm 1.5$ & .33 \\
\hline $\mathrm{n}$ & 68 & 65 & \\
\hline \multicolumn{4}{|l|}{5 years } \\
\hline $\mathrm{IOP}(\mathrm{mm} \mathrm{Hg})$ & $14.4 \pm 6.9$ & $12.6 \pm 5.9$ & .12 \\
\hline Glaucoma medications & $1.4 \pm 1.3$ & $1.2 \pm 1.5$ & .23 \\
\hline $\mathrm{n}$ & 61 & 63 & \\
\hline
\end{tabular}

$\mathrm{IOP}=$ intraocular pressure

Data presented as mean \pm standard deviation.

Data censored after a reoperation for glaucoma.

${ }^{a}$ Student t-test 
Table 3

Treatment Outcomes After 5 Years of Follow-up in the Tube Versus Trabeculectomy Study

\begin{tabular}{|c|c|c|}
\hline & Tube Group $(n=73)$ & Trabeculectomy Group $(n=84)$ \\
\hline \multicolumn{3}{|c|}{ Stratum 1 -previous cataract extraction } \\
\hline Failure & $8(26)$ & $23(59)$ \\
\hline Qualified success & $15(48)$ & $10(26)$ \\
\hline Complete success & $8(26)$ & $6(15)$ \\
\hline \multicolumn{3}{|c|}{$\begin{array}{l}\text { Stratum 2-previous trabeculectomy or combined procedure without an } \\
\text { antifibrotic agent }\end{array}$} \\
\hline Failure & $8(47)$ & $8(47)$ \\
\hline Qualified success & $6(35)$ & $1(6)$ \\
\hline Complete success & $3(18)$ & $8(47)$ \\
\hline \multicolumn{3}{|c|}{$\begin{array}{l}\text { Stratum 3-previous trabeculectomy with 5-FU or combined procedure with 5- } \\
\text { FU or MMC }\end{array}$} \\
\hline Failure & $1(8)$ & $5(36)$ \\
\hline Qualified success & $4(33)$ & $3(21)$ \\
\hline Complete success & $7(58)$ & $6(43)$ \\
\hline \multicolumn{3}{|c|}{ Stratum 4-previous trabeculectomy with MMC } \\
\hline Failure & $7(54)$ & $6(43)$ \\
\hline Qualified success & $6(46)$ & $4(29)$ \\
\hline Complete success & 0 & $4(29)$ \\
\hline \multicolumn{3}{|l|}{ Overall group } \\
\hline Failure $^{a}$ & $24(33)$ & $42(50)$ \\
\hline Qualified success & $31(42)$ & $18(21)$ \\
\hline Complete success $b$ & $18(25)$ & $24(29)$ \\
\hline
\end{tabular}

5-FU = 5-fluorouracil; $\mathrm{MMC}=$ mitomycin $\mathrm{C}$

Data presented as number of patients (percentage).

${ }^{a} \mathrm{P}=.034$ for the difference in failure rates between treatment groups (chi-square test adjusted for stratum)

${ }^{b} \mathrm{P}=.58$ for the difference in complete success rates between treatment groups (chi-square test adjusted for stratum) 


\section{Table 4}

Reasons for Treatment Failure in the Tube Versus Trabeculectomy Study

\begin{tabular}{|l|c|c|}
\hline & Tube Group (n= 24) & Trabeculectomy Group (n = 42) \\
\hline Inadequate IOP reduction $^{a}, b$ & $13(54)$ & $17(40)$ \\
\hline Reoperation for glaucoma & $7(29)$ & $11(26)$ \\
\hline Persistent hypotony $c$ & $3(13)$ & $13(31)$ \\
\hline Loss of light perception & $1(4)$ & $1(2)$ \\
\hline
\end{tabular}

$\mathrm{IOP}=$ intraocular pressure

Data are presented as number (percentage).

$a_{\mathrm{IOP}}>21 \mathrm{~mm} \mathrm{Hg}$ or not reduced by $20 \%$ below baseline on 2 consecutive follow-up visits after 3 months

${ }^{b}$ Some patients underwent reoperation for glaucoma subsequent to failure because of inadequate IOP reduction.

${ }^{c}$ IOP $\leq 5 \mathrm{~mm} \mathrm{Hg}$ on 2 consecutive follow-up visits after 3 months

$\mathrm{P}=.43$ for the difference in distribution of reasons for failure between treatment groups (exact permutation chi-square test) 
Table 5

Risk Factor Analysis for Failure in the Tube Versus Trabeculectomy Study

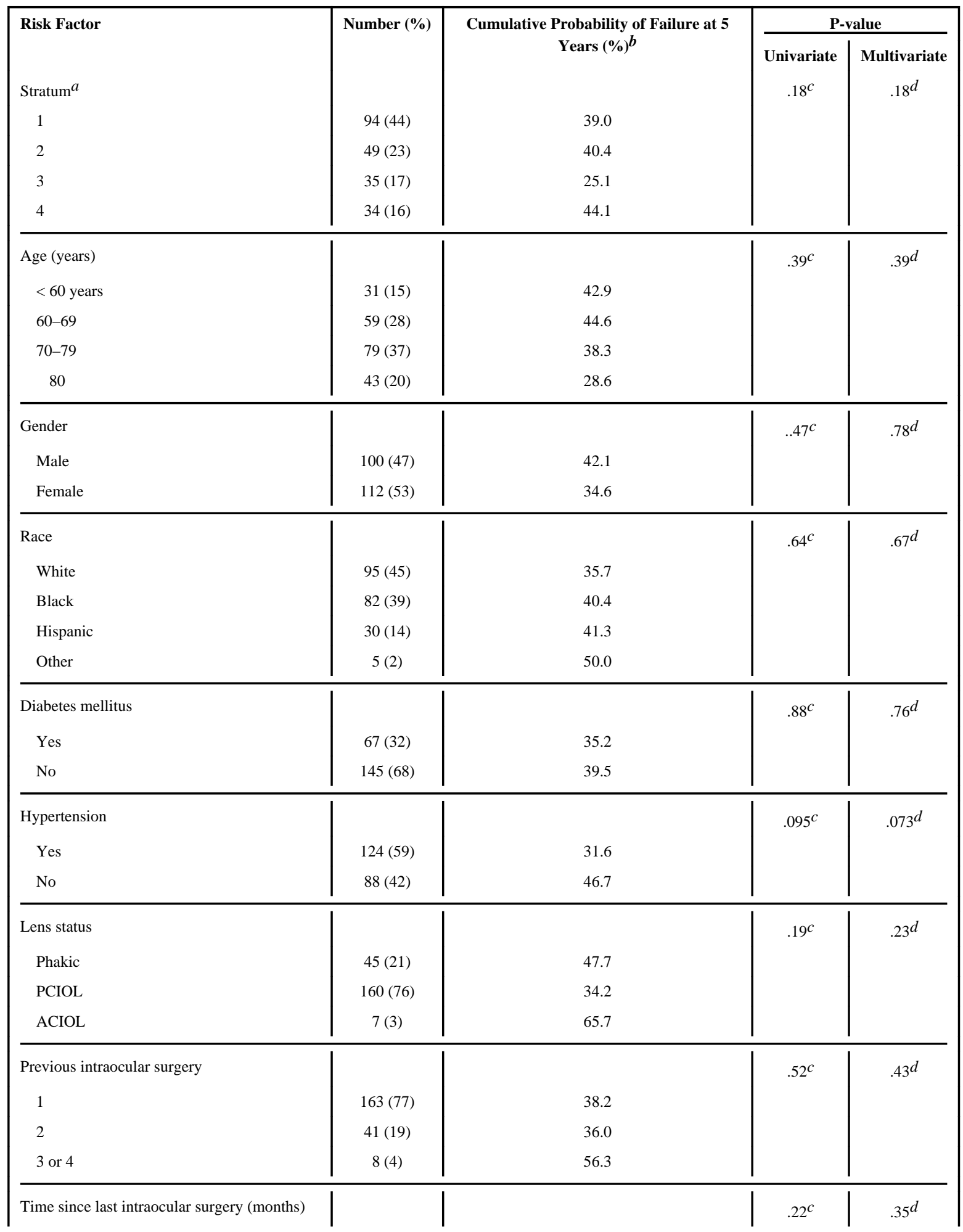




\begin{tabular}{|c|c|c|c|c|}
\hline \multirow[t]{2}{*}{ Risk Factor } & \multirow[t]{2}{*}{ Number (\%) } & \multirow{2}{*}{$\begin{array}{c}\text { Cumulative Probability of Failure at } 5 \\
\text { Years }(\%)^{b}\end{array}$} & \multicolumn{2}{|c|}{ P-value } \\
\hline & & & Univariate & Multivariate \\
\hline$<6$ months & $15(7)$ & 47.5 & & \\
\hline$\geq 6$ months & $190(93)$ & 38.1 & & \\
\hline Glaucoma type & & & $.99^{c}$ & $.76^{d}$ \\
\hline Primary & $190(90)$ & 37.1 & & \\
\hline Secondary & $22(10)$ & 47.5 & & \\
\hline Preoperative number of glaucoma medications & & & $.97^{c}$ & $.97^{d}$ \\
\hline $0-1$ & $21(10)$ & 35.7 & & \\
\hline $2-3$ & $108(51)$ & 40.9 & & \\
\hline $4-6$ & $83(39)$ & 35.2 & & \\
\hline Preoperative IOP (mm Hg) & & & $.60^{c}$ & $.59^{d}$ \\
\hline$<23$ & $77(36)$ & 36.1 & & \\
\hline $23-26$ & $66(31)$ & 42.8 & & \\
\hline$>26$ & $69(33)$ & 39.3 & & \\
\hline Preoperative Snellen VA & & & $.21^{c}$ & $.17^{d}$ \\
\hline$\geq 20 / 30$ & $106(50)$ & 31.6 & & \\
\hline 20/40-20/150 & $74(35)$ & 39.8 & & \\
\hline$\leq 20 / 200$ & $32(15)$ & 64.4 & & \\
\hline Clinical Centers & & & $.81^{c}$ & $.95^{d}$ \\
\hline Enrolled $250 \%$ patients & $133(63)$ & 41.4 & & \\
\hline Enrolled $<50 \%$ patients & $79(37)$ & 32.6 & & \\
\hline Treatment & & & $.002^{c}$ & - \\
\hline Tube & $107(50)$ & 29.8 & & \\
\hline Trabeculectomy & $105(50)$ & 46.9 & & \\
\hline
\end{tabular}

$\mathrm{ACIOL}=$ anterior chamber intraocular lens; $\mathrm{IOP}=$ intraocular pressure; $\mathrm{PCIOL}=$ posterior chamber intraocular lens; $\mathrm{VA}=$ visual acuity

${ }^{a}$ Stratum 1 = previous cataract extraction; stratum 2 = previous trabeculectomy or combined procedure without an antifibrotic agent; stratum $3=$ previous trabeculectomy with 5-fluorouracil or combined procedure with 5-fluorouracil or mitomycin C; stratum $4=$ previous trabeculectomy with mitomycin C

${ }^{b}$ Kaplan-Meier survival analysis

$c_{\text {Log rank test }}$

${ }^{d}$ Cox proportional hazard regression analysis, p-value adjusted for treatment 


\section{Table 6}

Reoperations for Glaucoma in the Tube Versus Trabeculectomy Study

\begin{tabular}{|l|c|c|}
\hline & Tube Group (n= 107) & Trabeculectomy Group (n= 105) \\
\hline Tube shunt & 4 & 15 \\
\hline Transscleral cyclophotocoagulation & 4 & 1 \\
\hline Endocyclophotocoagulation and cataract extraction & 1 & 0 \\
\hline Bleb revision and tube shunt & 0 & 2 \\
\hline Trabeculectomy with 5-FU & 0 & 1 \\
\hline $\begin{array}{l}\text { Total number of patients (cumulative percentage) with reoperation for } \\
\text { glaucoma }\end{array}$ & $8^{b}(9)$ & $18^{b}(29)$ \\
\hline
\end{tabular}

5-FU $=5$-fluorouracil

Data are presented as number of patients.

${ }^{a} \mathrm{P}=.025$ for the difference in 5-year cumulative reoperation rates for glaucoma between treatment groups from Kaplan-Meier analysis (log rank test adjusted for stratum)

$b_{1}$ patient had 2 different types of reoperations for glaucoma. 
Table 7

Visual Acuity Results in the Tube Versus Trabeculectomy Study

\begin{tabular}{|c|c|c|c|}
\hline & Tube Group (n = 107) & Trabeculectomy Group $(\mathrm{n}=105)$ & P-value \\
\hline \multicolumn{4}{|l|}{ ETDRS VA, mean $\pm S D(n)$} \\
\hline Baseline & $63 \pm 24(107)$ & $64 \pm 20(105)$ & $.56^{d}$ \\
\hline 5 years & $40 \pm 34(37)$ & $53 \pm 27(41)$ & $.068^{d}$ \\
\hline Change & $15 \pm 26(37)$ & $14 \pm 25$ (41) & $.83^{d}$ \\
\hline \multicolumn{4}{|l|}{ Snellen VA, $\log M A R$ mean \pm SD (n) } \\
\hline Baseline & $.42 \pm .54(107)$ & $.37 \pm .38(105)$ & $.40^{d}$ \\
\hline 5 years & $.85 \pm .97(67)$ & $.65 \pm .73(76)$ & $.15^{d}$ \\
\hline Change & $.38 \pm .72(67)$ & $.34 \pm .60(76)$ & $.73^{d}$ \\
\hline Loss of $\geq 2$ Snellen lines, $\mathrm{n}(\%)^{a, b}$ & $31^{c}(46)$ & $33(43)$ & $.93^{e}$ \\
\hline Glaucoma & 12 & 14 & \\
\hline Macular disease & 5 & 5 & \\
\hline Cataract & 2 & 3 & \\
\hline Other & 10 & 16 & \\
\hline Unknown & 5 & 2 & \\
\hline
\end{tabular}

ETDRS $=$ Early Treatment Diabetic Retinopathy Study; SD = standard deviation; VA = visual acuity

$a_{5 \text {-year rate of visual acuity }}$

${ }^{b}$ Some patients had more than 1 reason for decreased vision.

${ }^{c} 1$ patient who did not have Snellen VA measured at 5 years was determined to have lost $>2$ Snellen lines based on change in ETDRS VA.

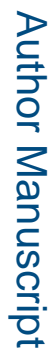

$d_{\text {Student t-test }}$

${ }^{e}$ Chi-square test 